\title{
Reclassification of Brucella ciceri as later heterotypic synonyms of Brucella intermedia
}

\author{
Ayixon Sánchez-Reyes*
}

*Cátedras Conacyt-Instituto de Biotecnología, Universidad Nacional Autónoma de México. Av. Universidad 2001, Chamilpa, 62210 Cuernavaca, Morelos, México. https://orcid.org/0000-00026749-5883. ayixon.sanchez@mail.ibt.unam.mx

\begin{abstract}
Recently Hördt et al. 2020 proposed to merge Ochrobactrum and Brucella genera based on up to date phylogenomic evidence and overall genomic divergence among BrucellaOchrobactrum clade. This led to the description of the new combinations Brucella ciceri comb. nov., basonym: Ochrobactrum ciceri Imran et al. 2010 and Brucella intermedia comb. nov., basonym: Ochrobactrum intermedium Velasco et al. 1998. However, the type species for Brucella ciceri DSM $22292^{\mathrm{T}}$ and Brucella intermedia LMG $3301^{\mathrm{T}}$ show whole-genome coherence at the species level $(\mathrm{ANI}=98.21 \%$, Mash $\mathrm{D}=0.0154006, \mathrm{dDDH}$ relatedness $>70 \%$ ), suggesting that may belong to the same genomospecies. Also, both taxa formed a single clade in the phylogenomic tree based on single-copy gene sequences. Previously reported phenotypic data offer a context where both taxa are highly related supporting this synonymy. Therefore, Brucella ciceri should be reclassified as later heterotypic synonyms of Brucella intermedia, which has priority. The species description is consequently amended.
\end{abstract}

Keywords: Ochrobactrum; Brucella; Genome-based taxonomy; Overall genome relatedness index.

Abbreviations: ANI: average nucleotide identity; dDDH, digital DNA-DNA hybridization; Mash D: mutation distance estimated by Mash. 


\section{Introduction}

Brucella genus Meyer and Shaw 1920 (Approved Lists 1980) (1) is a member of the $\alpha$ Proteobacteria class, with several species historically recognized as virulent for humans. At present, possess 25 child taxa with validly published names and a least five synonyms. Recently, Hördt et al. (2) analyzed more $1000 \alpha$-Proteobacteria type-strain genome composites, and suggested major emendation's for many species according to phylogenetic features, resting on genomic data. One of the changes suggested by these authors includes the genus Ochrobactrum Holmes et al. 1988 (3) as part of the Brucella group, as well as type species of Ochrobactrum seems to be a clade more closely related to Brucella. These changes were validated in the announcement of new names and new combinations published by Oren and Garrity. (4), so, Ochrobactrum actually constitutes a synonym of Brucella. This led to the description of the new combinations Brucella ciceri comb. nov., basonym: Ochrobactrum ciceri Imran et al. 2010 (5) and Brucella intermedia comb. nov., basonym: Ochrobactrum intermedium Velasco et al. 1998 (6).

However, during a comparative analysis of 30 environmental genomes of the Brucellaceae family (unpublished data), arose that the type species for B. ciceri DSM $22292^{\mathrm{T}}$ and $B$. intermedia $\mathrm{LMG} 3301^{\mathrm{T}}$ share whole-genome coherence at the species level (ANI $=98.21 \%$, Mash $\mathrm{D}=0.0154006$, dDDH relatedness $>70 \%$ ), suggesting that may belong to the same genomospecies. Both taxa formed a single clade in the phylogenomic tree based on single-copy gene sequences and form a single species-specific cluster according to several genomic properties. In an independent study, Ashford et al. (7) also found high levels of similarity between type strains of synonym's $O$. ciceri and $O$. intermedium and cautiously suggest a possible re-classification as a single species. Therefore, this note formally proposes that Brucella ciceri DSM $22292^{\mathrm{T}}$ should be reclassified as later heterotypic synonyms of Brucella intermedia $\mathrm{LMG} 3301^{\mathrm{T}}$ which has priority and present an emended species description.

\section{Materials and Methods}

\section{Determination of closely related type strains:}

The B. ciceri DSM $22292^{\mathrm{T}}$ query genome was compared against all type strain genomes accessible in the Type (Strain) Genome Server (TYGS) (https://tygs.dsmz.de) (8), through the MASH tool, which estimate the mutational rate between representative MinHash sketches (9). The ten type strains hits with the lowest MASH distances were chosen for further analysis 
using the Genome BLAST Distance Phylogeny approach (GBDP) under the algorithm 'coverage' and distance formula d5 (10).

\section{Pairwise comparison of genome sequences}

All pairwise genome comparisons were executed using GBDP distance functions. Digital DDH values and confidence intervals were calculated using the recommended settings of the GGDC 2.1 (10). The type-based species clustering was performed employing a 70\% dDDH radius among strains with standing in nomenclature. Average nucleotide identity was calculated with fastANI algorithm (11).

\section{Phylogenetic inference}

A minimum evolution tree was inferred via FASTME 2.1.4 according to (12). Branch support values were inferred with 100 pseudo-bootstrap replicates each. The trees were rooted at the midpoint.

\section{Results and discussion}

Whole-genome similarity metrics help to solve taxonomic issues, through the comparison of conserved sequence elements among different genomes. In this work, I have applied several alignment-free sequence mapping tools, to estimate the correct taxonomic status for the strain B. ciceri DSM $22292^{\mathrm{T}}$ (Alphaproteobacteria; Rhizobiales; Brucellaceae). Contrary to what is established, B. ciceri DSM $22292^{\mathrm{T}}$ does not appear to be a separate species within the Brucellaceae family; it shares $\sim 0.015$ of Mash distance and $\sim 98.2 \%$ of ANI with all $B$. intermedia types genomes, confirming a clear intra-species boundaries prevalence between these two strains (Table 1). As expected, Mash distance $\leq 0.05$ correlates well with ANI, and both metrics support species-specific delineation in prokaryotes. These results also reveal a clear genetic gap among all B. intermedia types genomes and the rest of the genomes analyzed for the genus, which allows clustering according to genome similarity $(9,11)$.

Table 1. Genomic distance estimation using MinHash

\begin{tabular}{|c|c|c|c|c|c|}
\hline Query Strain & $\begin{array}{l}\text { Reference } \\
\text { GenBank assembly } \\
\text { accession }\end{array}$ & Organism & $\begin{array}{l}\text { Mash distance } \\
\text { (D) }\end{array}$ & $\begin{array}{l}\text { Matching } \\
\text {-hashes }\end{array}$ & $\begin{array}{l}\text { ANI } \\
(\%)\end{array}$ \\
\hline \multirow{4}{*}{$\begin{array}{c}\text { Brucella ciceri DSM } \\
22292^{\mathrm{T}} \\
\text { GCA_012103155.1 }\end{array}$} & GCA_900454225.1 & Brucella intermedia $\mathrm{NCTC} 12171^{\mathrm{T}}$ & 0.015400 & $567 / 1000$ & 98.2185 \\
\hline & GCA_000182645.1 & Brucella intermedia LMG 3301 & 0.015454 & $566 / 1000$ & 98.1922 \\
\hline & GCA_012103055.1 & Brucella intermedia CIP $105838^{\mathrm{T}}$ & 0.016163 & $553 / 1000$ & 98.1746 \\
\hline & GCA_008932295.1 & Brucella tritici LMG $18957^{\mathrm{T}}$ & 0.111970 & $50 / 1000$ & 88.0041 \\
\hline
\end{tabular}




\begin{tabular}{llllc}
\hline GCA_006376675.1 & Brucella pecoris 08RB2639 & 0.112887 & $49 / 1000$ & 87.0140 \\
\hline GCA_900454235.1 & Brucella anthropi NCTC 12168 & 0.113823 & $48 / 1000$ & 87.8526 \\
\hline GCA_000017405.1 & Brucella anthropi ATCC 49188 & 0.113823 & $48 / 1000$ & 87.8329 \\
\hline GCA_012395285.1 & Brucella pecoris DSM 23868 & 0.113823 & $48 / 1000$ & 87.0501 \\
\hline GCA_002252535.1 & Brucella lupini LUP21 & 0.114780 & $47 / 1000$ & 87.9690 \\
\hline GCA_012103075.1 & Brucella cytisi LMG 22713 & 0.116760 & $45 / 1000$ & 87.5512 \\
\hline GCA_012103035.1 & Brucella oryzae NBRC 102588 & 0.124491 & $38 / 1000$ & 87.3619 \\
\hline
\end{tabular}

The estimation of DNA-DNA hybridization in-silico offers a compelling indication of the species-specific relationship between $B$. ciceri and B. intermedia (Table 2). The dDDH (genome-to-genome) comparison shows that the strain DSM $22292^{\mathbf{T}}$ was assigned to the $B$. intermedia species cluster; with all dDDH metrics suggesting a reliable demarcation (CI and $\mathrm{dDDH}>80 \%$ ). Also, both strains share minimal $\mathrm{G}+\mathrm{C}$ difference supporting they belong to the same species (10).

Table 2: Pairwise comparisons of Brucella ciceri DSM 22292 ${ }^{\mathrm{T}}$ genome vs. related type strain genomes. The table is ordered by column $\mathrm{dDDH}(\mathrm{d} 4)$ in descending order

\begin{tabular}{|c|c|c|c|c|c|c|c|}
\hline Subject strain & $\begin{array}{l}\text { dDDH } \\
(d 0, \%)\end{array}$ & $\begin{array}{c}\text { C.I. } \\
(\mathrm{d} 0, \%)\end{array}$ & $\begin{array}{l}\text { dDDH } \\
(\mathrm{d} 4, \%)\end{array}$ & $\begin{array}{c}\text { C.I. } \\
(d 4, \%)\end{array}$ & $\begin{array}{c}\text { dDDH } \\
(\mathrm{d} 6, \%)\end{array}$ & $\begin{array}{c}\text { C.I. } \\
(\mathrm{d6}, \%)\end{array}$ & $\begin{array}{c}\mathbf{G}+\mathbf{C} \\
\text { difference }(\%)\end{array}$ \\
\hline $\begin{array}{l}\text { Brucella intermedia } \\
\text { LMG } 3301\end{array}$ & 94 & $\begin{array}{l}91.5- \\
95.8]\end{array}$ & 85.3 & $\begin{array}{c}82.6- \\
87.7]\end{array}$ & 94.9 & $\begin{array}{c}{[93.0-} \\
96.3]\end{array}$ & 0.01 \\
\hline Brucella lupini LUP21 & 56.1 & $\begin{array}{l}{[52.6-} \\
59.6]\end{array}$ & 33.5 & $\begin{array}{l}{[31.1-} \\
36.0]\end{array}$ & 50.2 & $\begin{array}{c}{[47.1-} \\
53.3]\end{array}$ & 1.39 \\
\hline $\begin{array}{l}\text { Brucella tritici LMG } \\
18957\end{array}$ & 60.9 & $\begin{array}{c}{[57.2-} \\
64.4]\end{array}$ & 33.5 & $\begin{array}{l}{[31.1-} \\
36.0]\end{array}$ & 53.7 & $\begin{array}{c}{[50.6-} \\
56.8]\end{array}$ & 1.82 \\
\hline $\begin{array}{l}\text { Brucella anthropi } \\
\text { ATCC } 49188\end{array}$ & 60 & $\begin{array}{c}{[56.3-} \\
63.5]\end{array}$ & 33.4 & $\begin{array}{c}{[30.9-} \\
35.9]\end{array}$ & 53 & $\begin{array}{c}{[49.9-} \\
56.1]\end{array}$ & 1.61 \\
\hline $\begin{array}{l}\text { Brucella cytisi LMG } \\
22713\end{array}$ & 58.2 & $\begin{array}{c}{[54.6-} \\
61.8]\end{array}$ & 32.8 & $\begin{array}{c}{[30.4-} \\
35.3]\end{array}$ & 51.4 & $\begin{array}{c}{[48.4-} \\
54.5]\end{array}$ & 2.13 \\
\hline $\begin{array}{l}\text { Brucella oryzae NBRC } \\
102588\end{array}$ & 55.2 & $\begin{array}{c}{[51.7-} \\
58.7]\end{array}$ & 32.3 & $\begin{array}{c}{[29.9-} \\
34.8]\end{array}$ & 49 & $\begin{array}{c}{[45.9-} \\
52.0]\end{array}$ & 1.63 \\
\hline $\begin{array}{l}\text { Brucella pecoris DSM } \\
23868\end{array}$ & 59.3 & $\begin{array}{c}{[55.6-} \\
62.8]\end{array}$ & 31.6 & $\begin{array}{c}{[29.2-} \\
34.1]\end{array}$ & 51.6 & $\begin{array}{c}{[48.5-} \\
54.7]\end{array}$ & 1.78 \\
\hline $\begin{array}{l}\text { Brucella pecoris } \\
\text { 08RB2639 }\end{array}$ & 59.3 & $\begin{array}{c}{[55.6-} \\
62.8]\end{array}$ & 31.6 & $\begin{array}{c}{[29.2-} \\
34.1]\end{array}$ & 51.6 & $\begin{array}{c}{[48.5-} \\
54.6]\end{array}$ & 1.78 \\
\hline
\end{tabular}

Finally, GBDP tree reconstruction recognizes both strains as the same species cluster. Besides, the count of features like genomics size and protein count is similar (Figure 1). These observations confirm from the genomic point of view, a previous annotation made by $(7,13)$, in which B. ciceri and B. intermedia could not be discriminated as different species based solely 
on traits such as $16 \mathrm{~S}$ ribosomal gene identity, habitat or lifestyle.
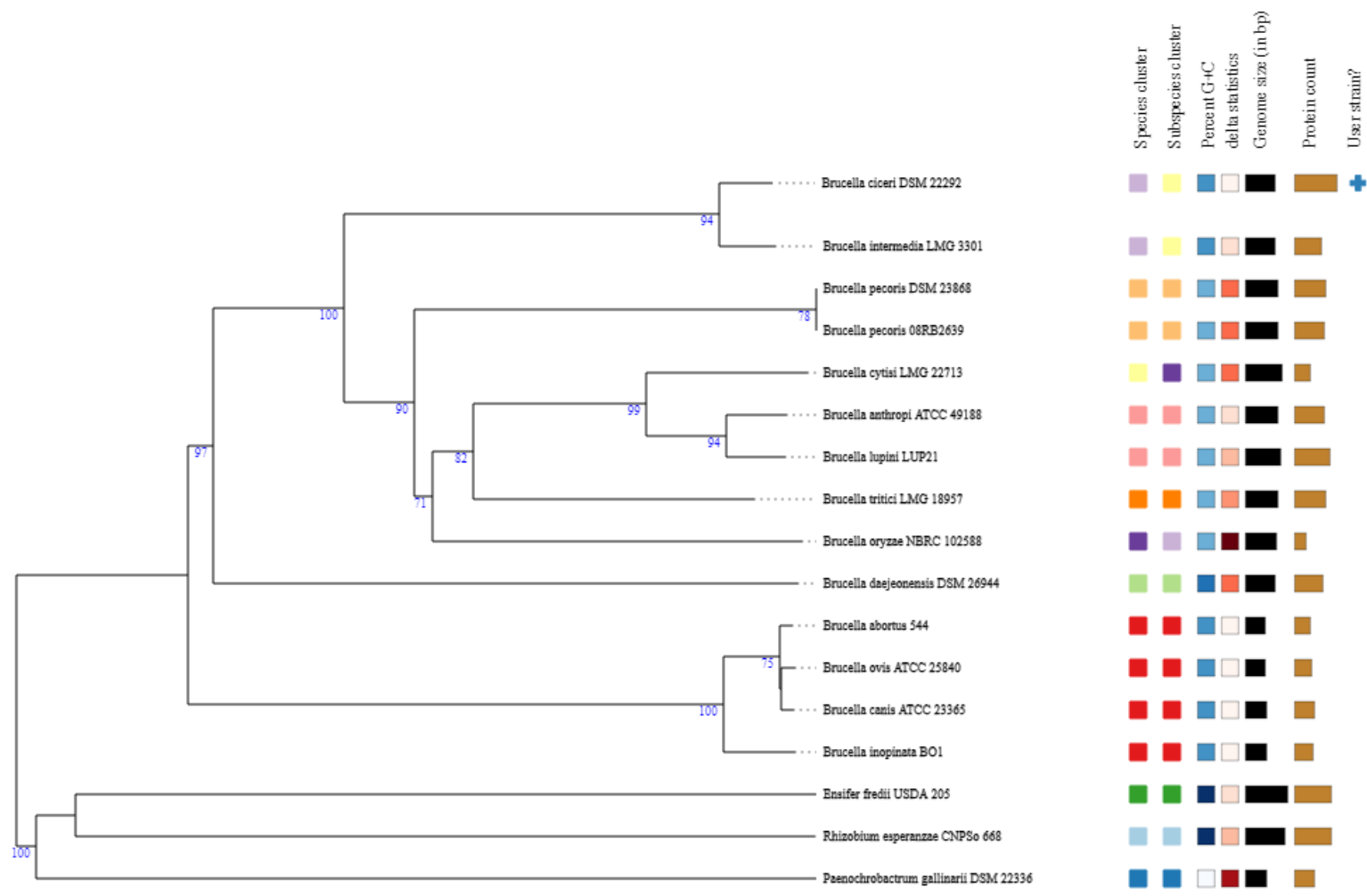

Figure 1. Tree inferred with FastME 2.1.6.1 from GBDP distances calculated from genome sequences. The branch lengths are scaled in terms of GBDP distance formula d5. The numbers above branches are GBDP pseudo-bootstrap support values $>60 \%$ from 100 replications, with average branch support of $80.5 \%$. The tree was rooted at the midpoint.

In fact, the iterum O. intermedium/O. ciceri strains represent a diversified clonal population with the capacity to colonize different niches, from pathogenic lifestyle to plant and animal commensal. All these data are highly consistent with that $B$. ciceri DSM $22292^{\mathrm{T}}$ should be reclassified as later heterotypic synonyms of $B$. intermedia. On the other hand, this reclassification does not affect the current clinical terminology, given that Ochrobactrum intermedium synonym (correct name Brucella intermedia), has been related with major relevance as an opportunistic pathogen.

\section{Emended species description of Brucella intermedia}

To the description reported by Velasco et al., (1998), Imran et al., (2010) data are added. Variable reaction to glycogen, Tween 80, raffinose, L-rhamnose, trehalose, a-ketobutyric acid, succinamic acid, glucuronamide, alaninamide, L-threonine, and uridine. A positive reaction for gelatin hydrolysis may occur. Resistant to ampicillin, aztreonam, cefixime, and cephradine. 
The type strain is CCUG $24694=$ CIP $105838=$ DSM $17986=$ IFO $15820=$ LMG $3301=$ NBRC 15820= NCTC $12171=$ CCUG 57879= DSM 22292.

\section{Funding information}

The author received no specific grant from any funding agency

\section{Conflicts of interest}

The author declares that there are no conflicts of interest

\section{References}

1. Meyer KF, Shaw EB. A comparison of the morphologic, cultural and biochemical characteristics of $b$. abortus and b. melitensis. J Infect Dis. 1920;

2. Hördt A, López MG, Meier-Kolthoff JP, Schleuning M, Weinhold L-M, Tindall BJ, et al. Analysis of 1,000+ Type-Strain Genomes Substantially Improves Taxonomic Classification of Alphaproteobacteria. Front Microbiol. 2020. Available from: https://www.frontiersin.org/article/10.3389/fmicb.2020.00468/full

3. Holmes B, Popoff M, Kiredjian M, Kersters K. Ochrobactrum anthropi gen. nov., sp. nov. from human clinical specimens and previously known as group Vd. Int J Syst Bacteriol. 1988;

4. Oren A, Garrity G. List of new names and new combinations previously effectively, but not validly, published. Int J Syst Evol Microbiol. 2020.70(7):4043-9. Available from: https://www.microbiologyresearch.org/content/journal/ijsem/10.1099/ijsem.0.004244

5. Imran A, Hafeez FY, Frühling A, Schumann P, Malik KA, Stackebrandt E. Ochrobactrum ciceri sp. nov., isolated from nodules of Cicer arietinum. Int J Syst Evol Microbiol. 2010;60(7):1548-53.

6. Velasco J, Romero C, López-Goñi I, Leiva J, Dĩaz R, Moriyón I. Evaluation of the relatedness of Brucella spp. and Ochrobactrum anthropi and description of Ochrobactrum intermedium sp. nov., a new species with a closer relationship to Brucella spp. Int J Syst Bacteriol. 1998;

7. Ashford R, Muchowski J, Koylass M, Scholz H, Whatmore A. Application of Whole Genome Sequencing and Pan-Family Multi-Locus Sequence Analysis to Characterize Relationships Within the Family Brucellaceae. Front Microbiol. 2020;

8. Meier-Kolthoff JP, Göker M. TYGS is an automated high-throughput platform for state-of-the-art genome-based taxonomy. Nat Commun. 2019;

9. Ondov BD, Treangen TJ, Melsted P, Mallonee AB, Bergman NH, Koren S, et al. Mash: Fast genome and metagenome distance estimation using MinHash. Genome Biol [Internet]. 2016;17(1):1-14. Available from: http://dx.doi.org/10.1186/s13059- 


\section{6-0997-x}

10. Meier-Kolthoff JP, Auch AF, Klenk HP, Göker M. Genome sequence-based species delimitation with confidence intervals and improved distance functions. BMC Bioinformatics. 2013;

11. Jain C, Rodriguez-R LM, Phillippy AM, Konstantinidis KT, Aluru S. High throughput ANI analysis of $90 \mathrm{~K}$ prokaryotic genomes reveals clear species boundaries. Nat Commun. 2018;

12. Lefort V, Desper R, Gascuel O. FastME 2.0: A comprehensive, accurate, and fast distance-based phylogeny inference program. Mol Biol Evol. 2015;

13. Aujoulat F, Romano-Bertrand S, Masnou A, Marchandin H, Jumas-Bilak E. Niches, Population Structure and Genome Reduction in Ochrobactrum intermedium: Clues to Technology-Driven Emergence of Pathogens. Moreno E, editor. PLoS One [Internet]. 2014 Jan 17 [cited 2018 Mar 27];9(1):e83376. Available from:

http://dx.plos.org/10.1371/journal.pone.0083376 